\title{
A rare association of left pulmonary artery sling with Scimitar syndrome: Recurrent wheezing and respiratory distress in a pediatric patient
}

\author{
Sol pulmoner arter sling ve Scimitar sendromunun nadir birlikteliği: \\ Bir çocuk hastada tekrarlayan hırıltı ve solunum sıkıntısı

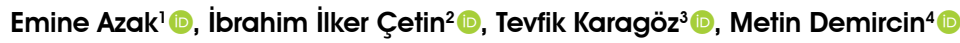 \\ Institution where the research was done: \\ University of Health Sciences, Ankara City Hospital, Ankara, Turkey \\ Author Affiliations: \\ 'Department of Pediatric Cardiology, University of Health Sciences, Ankara City Hospital, Ankara, Turkey \\ 2Department of Pediatric Cardiology, Yıldırım Beyazıt University Faculty of Medicine, Ankara, Turkey \\ 3Department of Pediatric Cardiology, Hacettepe University Faculty of Medicine, Ankara, Turkey \\ ${ }^{4}$ Department of Cardiovascular Surgery, Hacettepe University Faculty of Medicine, Ankara, Turkey
}

\begin{abstract}
Congenital anomalies of the heart and great vessels may lead to localized recurrent pulmonary infections through different mechanisms. Pulmonary artery sling (left pulmonary artery originating from the right pulmonary artery) and Scimitar syndrome are rare causes of wheezing in infants. An 18-month-old female infant with left pulmonary artery sling, Scimitar syndrome, and an anomalous connection of left pulmonary veins to the left atrium was admitted to our clinic. She successfully underwent transcatheter embolization using the Vascular Plug-II on the anomalous systemic arterial supply and repair of pulmonary arterial sling and Scimitar anomaly via a median sternotomy. In conclusion, diagnosis of left pulmonary arterial sling accompanied by abnormalities can be missed in some cases using echocardiography. It may be necessary to conduct more advanced imaging methods before deciding the treatment method to be performed in these patients.
\end{abstract}

Keywords: Anomalous pulmonary veins, computed tomography angiography, pulmonary artery sling, Scimitar syndrome, vascular plug-II.

Congenital anomalies of the great intrathoracic vessels leading to extrinsic airway narrowing typically include a double aortic arch, innominate artery compression, pulmonary artery slings, and

\section{$\ddot{O} Z$}

Kalbin ve büyük damarların doğumsal anomalileri, farklı mekanizmalar ile tekrarlayan lokalize pulmoner enfeksiyonlara yol açabilir.Pulmonar arter sling (sol pulmoner arterin sağdan köken alması) ve Scimitar sendromu, bebeklerde hirıltılı solunumun nadir nedenlerindendir. Sol pulmoner arter sling, Scimitar sendromu ve sol pulmoner venlerin sol atriyuma anormal bağlantısı olan 18 aylık bir kız bebek kliniğimize başvurdu. Başarılı bir şekilde Vasküler Plug-II ile anormal sistemik arter kaynağ 1 transkateter yolla embolize edilerek, medyan sternotomi yoluyla pulmoner arter sling ve Scimitar anomalisi düzeltildi. Sonuç olarak, ekokardiyografi ile bazı olgularda anormalliklerin eşlik ettiği pulmoner arter sling tanısı gözden kaçırılabilir. Bu hastalarda yapılacak tedavi yöntemine karar vermeden önce, daha ileri görüntüleme yöntemlerinin uygulanması gerekebilir.

Anahtar sözcükler: Pulmoner ven anomalisi, bilgisayarlı tomografi anjiyografi, pulmoner arter sling, Scimitar sendromu, vasküler plug-II.

vascular rings consisting of the right aortic arch, and anomalous origin of the left subclavian artery and ligamentum arteriosus. During early infancy, children with tracheal obstruction present with symptoms of

Received: June 05, 2020 Accepted: October 04, 2020 Published online: January 13, 2021

Correspondence: Emine Azak, MD. SBÜ, Ankara Şehir Hastanesi, Çocuk Kardiyolojisi Kliniği, 06800 Çankaya, Ankara, Türkiye. Tel: +90 533 - 5765782 e-mail: azakemi@gmail.com 
wheezing, retractions, and a crowing stridor on both inspiration and expiration. There is commonly a history of recurrent pulmonary infections. Murmurs are usually neither present nor audible, and the condition is frequently misdiagnosed as croup, bronchitis, or asthma. ${ }^{[1,4]}$

Pulmonary arterial sling is a condition where the left pulmonary artery has an anomalous origin from the right pulmonary artery and a rare cause of pulmonary distress in children. Other additional abnormalities may also occur, including right-sided pulmonary hypoplasia and agenesis, as well as Scimitar syndrome. The clinical outcome depends on the associated tracheobronchial and cardiac abnormalities. ${ }^{[3-5]}$ Computed tomography (CT) angiography is an excellent tool for demonstrating left pulmonary arterial sling and its associated cardiovascular abnormalities, and it is the most favorable tool for preoperative assessment of left pulmonary arterial sling. ${ }^{[5]}$

To the best of our knowledge, only two cases of left pulmonary arterial sling accompanied by Scimitar syndrome have been described in the literature. In this article, we report the first pediatric case of Scimitar syndrome presenting with a pulmonary artery sling and an anomalous connection of left pulmonary veins to the left atrium with the common truncus.

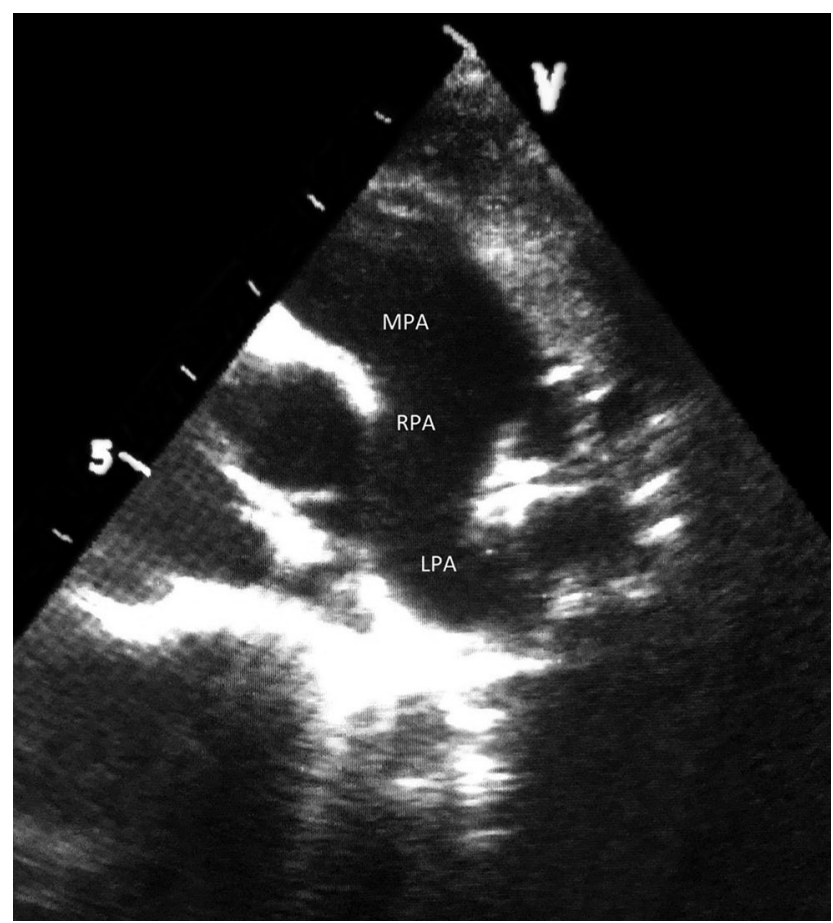

Figure 1. An echocardiographic image showing left pulmonary artery arising from distal segment of right pulmonary artery.

\section{CASE REPORT}

An 18-month-old infant was referred to our clinic for progressive respiratory distress, and frequent lower respiratory tract infections. Physical examination revealed tachypnea and a 2/6 grade systolic murmur. The chest X-ray showed hyperinflation and increased opacity in the right infrahilar region, suggesting an atelectasis, and shift of the trachea and the heart toward the right side. Electrocardiography showed right axis deviation and right ventricular dominance. The existence of left pulmonary arterial sling was suspected upon echocardiographic assessment. Echocardiographic image obtained in the parasternal short-axis view revealed that the left pulmonary artery was absent at its usual location. In addition, the main and pulmonary arteries in their regular orientations could not be visualized on echocardiography (Figure 1). There was partial abnormal venous drainage of the right pulmonary veins into the inferior vena cava (Scimitar vein) and enlarged right cardiac chambers. A CT angiography showed a dilated main pulmonary artery and anomalous origin of left pulmonary artery from the right pulmonary artery, which was compatible with the diagnosis of left pulmonary arterial sling. There was external compression on the right or left main bronchus as the left pulmonary artery coursed retrotracheally to the

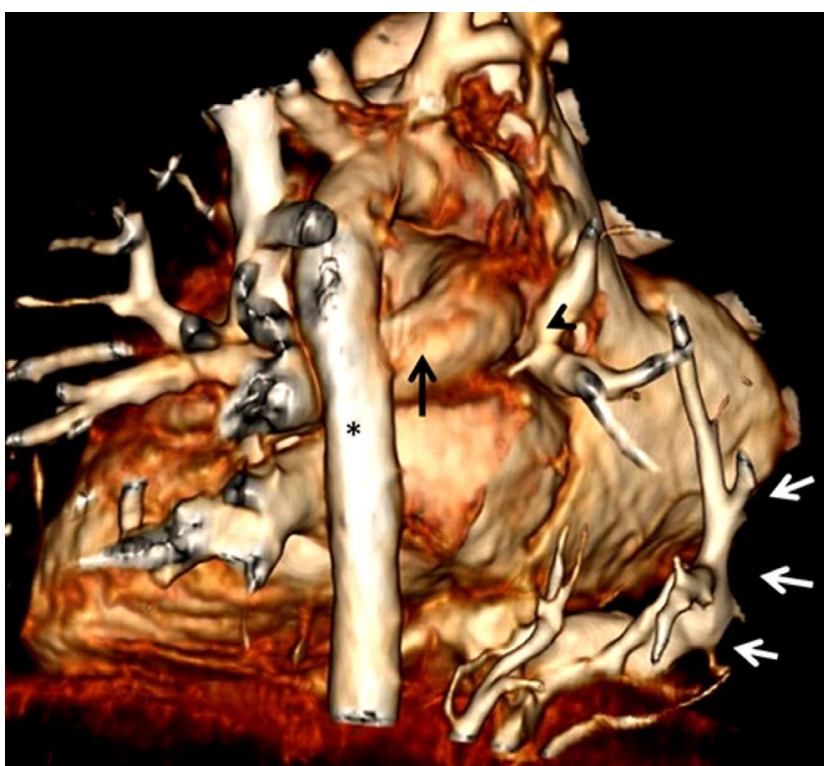

Figure 2. A computed tomography angiographic image. A three-dimensional volume rendering image showing abnormal venous drainage of right pulmonary veins into inferior vena cava (Scimitar vein; white arrows); left pulmonary arterial sling (black arrow); and hypoplastic right pulmonary vein (black arrowhead) (black star; aorta). 

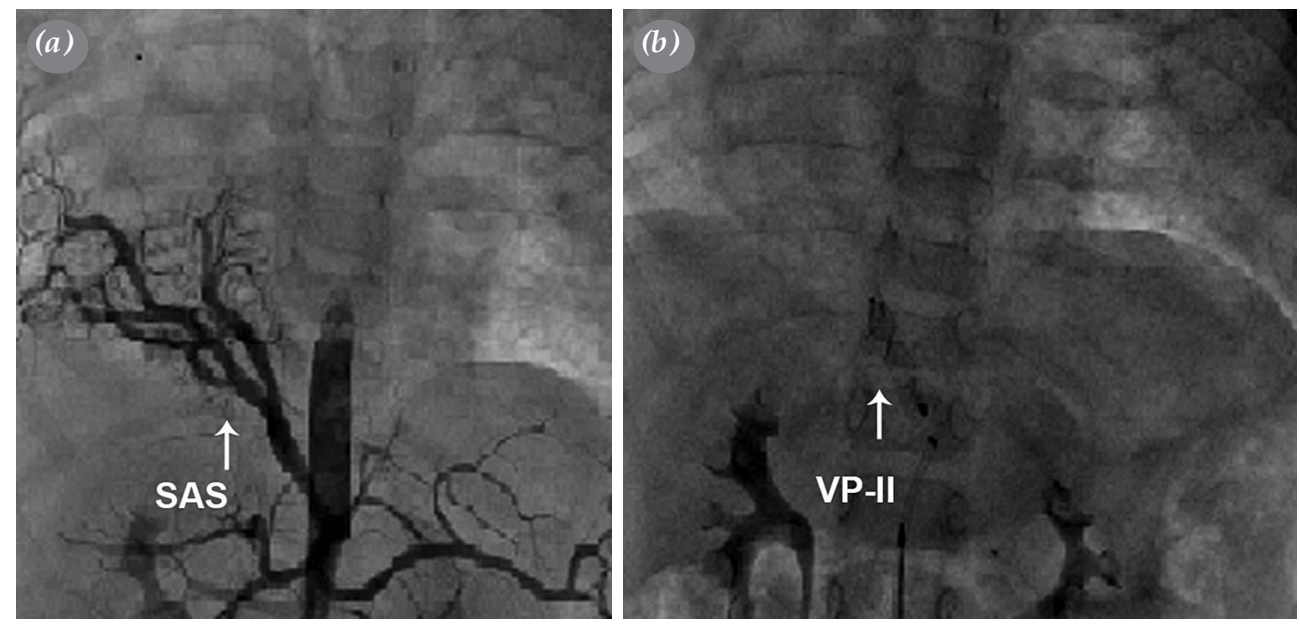

Figure 3. Cardiac catheter angiography images. (a) Before the procedure, aorta and a large anomalous vessel (SAS) arising as adjacent to superior mesenteric artery. (b) After the procedure, embolization was achieved with an 8-mm VP-II device deployed in the anomalous vessel.

SAS: Systemic arterial supply; VP-II: Vascular Plug-II.

left pulmonary hilum, and the right lung and the right main bronchus were hypoplasic. The axial section at the level of left atrium showed one pulmonary vein ending in the left atrium on the left side and left pulmonary veins with common truncus opening into the left atrium (Figure 2). A single pulmonary vein was observed on the right side and this vein opened suprahepatically into the inferior vena cava (Scimitar vein). The CT angiography confirmed the partial anomalous pulmonary venous return of the right-sided pulmonary veins into the inferior vena cava with no dual connections, anomalous systemic arterial supply, and pulmonary hypertension. The patient successfully underwent transcatheter embolization with an 8-mm Amplatzer ${ }^{\mathrm{TM}}$ Vascular Plug-II (AVP-II; Abbott Laboratories, Abbott Park, IL, USA) on the anomalous systemic arterial supply (Figure 3). At 20 months of age, the patient underwent surgical repair of the left pulmonary arterial sling by re-implantation of the left pulmonary artery from the main pulmonary artery and disconnection of the right pulmonary venous collector and its re-implantation in the left atrium without the need for any other interventions. The patient has been doing well with a stable clinical condition. A written informed consent was obtained from each parent.

\section{DISCUSSION}

Cardiac and pulmonary diseases are so closely interrelated that it is often difficult to detect in young infants which is the primary offender. Based on the current evidence, a wheezing infant very likely suffers from primary pulmonary disease; however, congenital cardiovascular abnormalities can cause pulmonary symptoms which completely dominate the clinical picture, leading to an erroneous diagnosis. Congenital anomalies of the heart and great vessels may lead to localized recurrent pulmonary infections through three different mechanisms: (i) reduced blood supply and defective ventilation, as seen in lung parenchymal hypoplasia; (ii) altered venous pulmonary circulation as seen in congenital pulmonary vein stenosis; and (iii) extrinsic compression of the large airways by the great vessels. ${ }^{[1,2,4]}$ Although rare, the basis of cough and wheezing may be a vascular ring, aberrant right subclavian artery, double aortic arch, and pulmonary sling which encircles and compresses the trachea and/or esophagus. As illustrated in previous case reports, failure to recognize the true nature of the disease process may lead to unnecessary procedures and delays which can be life-threatening. ${ }^{[1-5]}$

Pulmonary arterial sling is caused by an anomalous origin of the left pulmonary artery from the posterior aspect of the right pulmonary artery, which courses between the trachea and esophagus to reach the left lung. ${ }^{[1-5]}$ There are two types of pulmonary arterial sling. Type 1 mostly compresses the distal trachea, and the right main bronchus and tracheal bronchus may be present. Type 2 is characterized by a more distally located left pulmonary arterial sling and abnormal bronchial branching. Pulmonary arterial sling is frequently associated with tracheal abnormalities, lung abnormalities, and intracardiac 
and extracardiac abnormalities. ${ }^{[6-9]}$ In general, the clinical outcome of these patients depends on the associated tracheobronchial and complex cardiac abnormalities. On the other hand, some patients may be asymptomatic. ${ }^{[3,4]}$ Congenital heart defects are found in $50 \%$ of pulmonary arterial sling cases, the most common being atrial and ventricular septal defects, patent ductus arteriosus, and tetralogy of Fallot. ${ }^{[10]}$ Most of the associated abnormalities have been reported more frequently with Type 2 rather than Type 1 pulmonary arterial sling. ${ }^{[4-6]}$ Chen et al. ${ }^{[6]}$ reported that patients presented with tracheal stenosis $(100 \%)$ with a high incidence of combined right tracheal bronchus (22\%), underdeveloped right lung (22\%), and left patent ductus arteriosus (39\%).

Review of the literature regarding cases of coexistence of pulmonary arterial sling and Scimitar syndrome, our case is the third case that has been reported. In our case, the coexistence of pulmonary arterial sling and Scimitar syndrome was also accompanied by the anomalous opening of the left pulmonary veins to the left atrium. Scimitar syndrome consists of a partial anomalous pulmonary venous drainage of right lung, right lung hypoplasia, dextroposition of heart, and anomalous systemic arterial supply from aorta or one of its branches to the right lung. Clinical presentation depends on the degree of pulmonary arterial hypertension, which is often secondary to left-to-right shunt from the pulmonary vein, coexisting intracardiac shunt, pulmonary hypoplasia, resulting in reduction of the vascular bed, and systemic arterial supply to the right lung. ${ }^{[3,7-12]}$ Complete correction by surgery remains the gold-standard treatment. However, a two-stage procedure with a transcatheter approach to Scimitar syndrome may be an alternative in selected cases. Embolization of the aberrant vessels as the first-stage intervention yields clinical improvement, and reduction of left-to-right shunt and pulmonary artery pressure. Various types of devices, such as ductal coils, AVP-II or AVP-IV, can be chosen for embolization of anomalous systemic arteries. ${ }^{[13]}$ In our case, we used an 8-mm AVP-II to close the anomalous arterial supply to the sequestered segments. The Amplatzer ${ }^{\mathrm{TM}}$ vascular plugs are effective, safe, and straightforward devices and, for pediatric applications, the major advantage is the reduced profile of the device, allowing small introducer sheath sizes. ${ }^{[11,13]}$ In our case, we used the AVP-II through a small guide catheter, which did not cause any arterial complication.

Vascular rings are complex, and diagnosis is often challenging due to variable and non-specific clinical presentations. Echocardiography has a limited role in the evaluation of vascular rings due to the small field of view, which is even more limited in patients with a poor thymic window or hyperinflated lungs, and is unable to detect rings without color flow Doppler or associated airway abnormalities. An accurate, CT angiography of the cardiac and related arterial anatomy is critical for the clinical management in children with complex congenital heart diseases. ${ }^{[12,14]}$

Although diagnosis of pulmonary arterial sling by echocardiography is almost always possible, it requires an increased alertness when other intracardiac and extracardiac disorders coexist. The CT angiography plays an important role in the identification and definition of the anatomy of these complex anomalies, thus providing a roadmap to surgeons. Associated airway anomalies can be also assessed using CT. ${ }^{[14]}$

The prognosis of pulmonary arterial sling is variable depending on the clinical presentation. Surgery is the standard of care for all patients with symptomatic vascular compression of the trachea or bronchi. ${ }^{[5,6]}$ In their case series including five infants with pulmonary sling associated intracardiac abnormalities, Oshima et al. ${ }^{[15]}$ recommended early primary repair of pulmonary arterial sling with tracheal stenosis and concomitant repair of congenital cardiac abnormalities, as well as tracheal stenosis, whenever possible. Children with pulmonary artery sling who have mild symptoms are frequently treated with conservative strategies in most of the medical centers. Unfortunately, the case presented herein and the mistakes committed along the way illustrate the shortcomings of a critical thinking mode which starts out on the wrong path with a biased judgment.

In conclusion, the assumption that all wheezing are a form of reactive airway disease in pediatric patients may result in misfortune for the patient, as a very rare, yet critically important disease entity can be overlooked. Echocardiography should be the modality of the first choice for the diagnosis. However, we are convinced that further imaging studies should be performed, since the treatment is ideally tailored based on accompanying tracheobronchial and cardiac abnormalities. To the best of our knowledge, this is the first pediatric case diagnosed with Scimitar syndrome along with a pulmonary artery sling and an anomalous connection of left pulmonary veins to the left atrium with the common truncus. This case report highlights the fact that one should keep an open mind regarding the definitive diagnosis in any child with recurrent wheeze, as all wheezes are not asthma. In particularly, infants or young children with recurrent respiratory 
symptoms such as chronic cough, stridor and wheeze should be examined for the possible presence of congenital vascular anomalies.

\section{Declaration of conflicting interests}

The authors declared no conflicts of interest with respect to the authorship and/or publication of this article.

\section{Funding}

The authors received no financial support for the research and/or authorship of this article.

\section{REFERENCES}

1. Robotin MC, Bruniaux J, Serraf A, Uva MS, Roussin R, Lacour-Gayet F, et al. Unusual forms of tracheobronchial compression in infants with congenital heart disease. J Thorac Cardiovasc Surg 1996;112:415-23.

2. Hislop AA. Airway and blood vessel interaction during lung development. J Anat 2002;201:325-34.

3. Gikonyo BM, Jue KL, Edwards JE. Pulmonary vascular sling: report of seven cases and review of the literature. Pediatr Cardiol 1989;10:81-9.

4. Xie J, Juan YH, Wang Q, Chen J, Zhuang J, Xie Z, et al. Evaluation of left pulmonary artery sling, associated cardiovascular anomalies, and surgical outcomes using cardiovascular computed tomography angiography. Sci Rep 2017;7:40042.

5. Newman B, Meza MP, Towbin RB, Nido PD. Left pulmonary artery sling: diagnosis and delineation of associated tracheobronchial anomalies with MR. Pediatr Radiol 1996;26:661-8.

6. Chen SJ, Lee WJ, Lin MT, Wang JK, Chang CI, Chiu IS, et al. Left pulmonary artery sling complex: computed tomography and hypothesis of embryogenesis. Ann Thorac Surg 2007;84:1645-50.
7. Backer CL, Russell HM, Kaushal S, Rastatter JC, Rigsby CK, Holinger LD. Pulmonary artery sling: current results with cardiopulmonary bypass. J Thorac Cardiovasc Surg 2012;143:144-51.

8. Huang SC, Wu ET, Wang CC, Chen SJ, Chen YS, Chang CI, et al. Surgical management of pulmonary artery sling: trachea diameter and outcomes with or without tracheoplasty. Pediatr Pulmonol 2012;47:903-8.

9. Wells TR, Gwinn JL, Landing BH, Stanley P. Reconsideration of the anatomy of sling left pulmonary artery: the association of one form with bridging bronchus and imperforate anus. Anatomic and diagnostic aspects. J Pediatr Surg 1988;23:892-8.

10. Hong X, Liu C, Zhou G, Liu Y, Wang H, Wang G, et al. Treatment of 21 pediatric children with pulmonary artery sling/tracheal stenosis: what kinds of patients can survive to discharge without tracheal intervention? Int J Clin Exp Med 2017;10:3588-93.

11. Demir F, Demir Hİ, Yücel İK, Dedeoğlu R, Erdem A, Aydemir NA, et al. Scimitar sendromu: Farklı klinik tablolar ve sonuçlar. Turk Gogus Kalp Dama 2014;22:305-11.

12. Song C, Jiang G, Ye J, He J, Yu J. Echocardiography in diagnosis of pediatric pulmonary artery sling. Zhejiang Da Xue Xue Bao Yi Xue Ban 2018;47:250-4.

13. Wang Z, Cai X. Transcatheter intervention in a child with scimitar syndrome. Cardiovasc J Afr 2016;27:e9-e11.

14. Li A, Peng Z, Zhang C. Comparison of echocardiography and 64-multislice spiral computed tomography for the diagnosis of pediatric congenital heart disease. Med Sci Monit 2017;23:2258-66.

15. Oshima Y, Yamaguchi $M$, Yoshimura N, Ogawa K, Nishijima E, Tsugawa C. Primary repair of pulmonary artery sling with double outlet right ventricle and distal tracheal stenosis. J Cardiovasc Surg (Torino) 2002;43:849-51. 